\title{
Network pharmacology of AYUSH recommended immune-boosting medicinal plants against COVID- 19
}

\section{Pukar Khanal}

Department of Pharmacology and Toxicology, KLE College of Pharmacy, Belagavi, KLE Academy of Higher Education and Research (KAHER), Belagavi-590010, Karnataka, India

\section{Taaza Duyu}

Department of Pharmacology and Toxicology, KLE College of Pharmacy, Belagavi, KLE Academy of Higher Education and Research (KAHER), Belagavi-590010, Karnataka, India

\section{Yadu Nandan Dey ( $\nabla$ yadunandan132@gmail.com )}

School of Pharmaceutical Technology, Adamas University, Kolkata-700126, West Bengal, India

\section{B M Patil}

Department of Pharmacology and Toxicology, KLE College of Pharmacy, Belagavi, KLE Academy of Higher Education and Research (KAHER), Belagavi-590010, Karnataka, India

\section{lasmail Pasha}

Department of Pharmacology, Orotta College of Medicine and Health Sciences, Asmara University, Asmara, Eritrea

\section{Manish Wanjari}

Regional Ayurveda Research Institute for Drug Development, Gwalior, Madhya Pradesh, India

\section{Research Article}

Keywords: AYUSH, COVID19, herbal tea, immunity promotion

Posted Date: May 27th, 2020

DOl: https://doi.org/10.21203/rs.3.rs-31776/v1

License: (c) (i) This work is licensed under a Creative Commons Attribution 4.0 International License. Read Full License

Version of Record: A version of this preprint was published on November 25th, 2020. See the published version at https://doi.org/10.1016/j.jaim.2020.11.004. 


\section{Abstract}

Background: The Ministry of AYUSH recommended the use of a decoction of the mixture of Ocimum tenuiflorum, Cinnamomum verum, Piper nigrum, Zingiber officinale, and Vitis vinifera as a preventive measure to boost immunity and to inhibit the severity of infection caused by a novel coronavirus (COVID19).

Objective: The present study aimed to identify the probable modulated pathways via AYUSH recommended formulation as an immune booster against COVID-19.

Materials and methods: Reported phytoconstituents of all the plants were retrieved from the ChEBI database, and their targets were predicted using DIGEP-Pred. STRING database and Cytoscape were used to predict the protein-protein interaction and construct the network interaction respectively. Likewise, MolSoft and admetSAR2.0 were used to predict the druglikeness score and ADMET profile of phytoconstituents.

Results: The study identified the modulation of HIF-1, p53, PI3K-Akt, MAPK, cAMP, Ras, Wnt, NF-kappa B, IL-17, TNF, and cGMP-PKG signaling pathways to boost the immune system. Further, multiple pathways were also identified which are involved in the regulation of pathogenesis of the multiple infections and non-infectious diseases due to the lower immune system.

Conclusion: Results indicated that the recommended herbal formulation not only modulated the pathways related to boost the immune system but also modulated the multiple pathways that are contributing in the progression of multiple disease pathogenesis which would add the beneficial effect in the special subjects like patients from hypertension and diabetes in which 4-hydroxychloroquine therapeutic approach cannot be made. The study provides the scientific documentation of the role of the Ayurvedic formulation to combat COVID-19.

\section{Introduction}

In the last 6 months, the novel coronavirus (COVID-19) has spread over the globe infecting more than 2 million populations leading to more than 100 thousand deaths. Subjects suffering from infectious and non-infectious diseases of the lungs are found to be more risk from this viral infection due to the lower immune system[1]. Hence, enhancing the immunity (natural body system) may possess the major contribution as a prophylactic measure against multiple pathogenic conditions as well as maintaining optimum health [2].

Ayurveda utilizes the concept of "Dinacharya" and "Ritucharya" to maintain healthy life that utilizes the gifts of nature (herbal medicines) as daily/seasonal regimes to maintain a healthy life [3]. Ayurveda; a plant-based science suggests in simplifying the lifestyle, and also promotes the awareness in uplifting and maintaining own's immune system via the utilization of many plants/herbs [3] which are easily available at the kitchen garden of a majority of the society. 
Based on the Ayurvedic and scientific literature, Ministry of AYUSH (Ayurveda, Yoga and Naturopathy, Unani, Siddha, and Homeopathy), India issued advisory where it recommended the use of Kadha (herbal tea/decoction) composed of Ocimum tenuiflorum (Tulsi), Cinnamomum verum (Dalchini), Piper nigrum (Kalimirch), Zingiber officinale (Shunthi) and Vitis vinifera (Munakka) for self-care which will develop immunity against severe infection caused by COVID-19. Further, it also recommended the consumption of golden milk; a half teaspoon of Curcuma longa (turmeric) powder in $150 \mathrm{ml}$ hot milk once or twice a day [3]. However, the scientific evidence of all these herbal combinations for boosting the immune system has not been proposed yet. Hence, in the present study, we proposed to elucidate the probable interaction of the phytoconstituents from individual ingredients of the AYUSH recommended formulation to boost the immune system by gene-set enrichment and network pharmacology approach to support with scientific shreds of evidence.

\section{Materials And Methods}

\subsection{Mining of phytoconstituents and their targets}

The phytoconstituents of 6 medicinal plants i.e. Cinnamomum verum, Curcuma longa, Ocimum tenuiflorum, Piper nigrum, Vitis Vinifera, Zingiber officinale were retrieved from ChEBI

(https://www.ebi.ac.uk/chebi/) database. The targets of each phytoconstituents were identified using DIGEP-Pred [4] for proteins at Probable activity $(\mathrm{Pa})>0.7$.

\subsection{Enrichment and Network analysis}

The list of probable targets was queried in STRING [5] database, and enrichment analysis of proteinprotein interaction was performed for biological process, molecular function, and cellular components. Further, the probably modulated pathways were also identified concerning the KEGG pathway database. Cytoscape [6] was used to construct the network among the plants, their phytoconstituents, modulated proteins, and regulated pathways. The network was treated as directed, node size as "Iow values to small sizes" and map node color from "low values to bright colors" and the whole network was analyzed based on edge count.

\subsection{Druglikeness and ADMET Profile}

Druglikeness score of each phytoconstituent was calculated based on Lipinski's rule of five [7] using MolSoft (https://molsoft.com/mprop/). Likewise, the probability for human intestinal absorption, caco-2, and blood-brain barrier permeability, human oral bioavailability, P-glycoprotein, CYP3A4, CYP2C9, CYP2D6, and CYP1A2 inhibition, eye irritation, Ames mutagenesis, human ether-a-go-go inhibition, and hepatotoxicity was predicted using admetSAR2.0 [8].

\section{Results}

\subsection{Phytoconstituents and their targets}


Total 221 phytoconstituents were identified in which 40 were from Cinnamomum verum, 27 from Curcuma longa, 3 from Ocimum tenuiflorum, 91 from Piper nigrum, 40 from Vitis vinifera, and 20 from Zingiber officinale in which 173 compounds were identified to modulate the proteins at $\mathrm{Pa}>0.7$. Among them, (-)-(3S)-1-(3,4-hydroxyphenyl)-7-(4-hydroxyphenyl)heptan-3-ol was predicted to have the highest interaction with multiple proteins i.e. 18. Likewise, MMP2 was predicted to be a majorly targeted protein by 58 phytoconstituents. The list of phytoconstituents and their source of each compound are summarized in Table S1. By these 173 phytoconstituents, a total of 524 interactions were made with multiple proteins. The complete interaction of the multiple phytoconstituents with their targets and regulated pathways is represented in Fig. 1.

\subsection{Gene set enrichment analysis}

Gene set enrichment analysis identified eighty different pathways to be modulated by the bioactives from the herbal tea. Phytoconstituents were also identified to regulate the proteins which were involved in multiple pathogeneses (infectious and non-infectious diseases) including immunology (Table S2). The protein-protein interaction of each modulated proteins and their gene $\mathrm{GO}$ analysis is represented in Fig. 2 and Fig. 3 respectively.

\subsection{Druglikeness and ADMET profile}

Among 221 phytoconstituents, eighty compounds were predicted to possess a positive druglikeness score in which camphoratin D from Cinnamomum verum scored highest druglikeness score i.e. 1.18 (Fig. 4). Among the 20 best hits from the list of phytoconstituents, all the compounds were predicted to get absorbed from the human intestinal tract. Among them, camphoratin B was predicted to have the highest oral bioavailability and was also predicted for the least toxicity profile like eye irritation, Ames mutagenesis, human either-a-go-go inhibition, and hepatotoxicity compared to rest of compounds (Fig. $5)$.

\section{Discussion}

Recently, AYUSH has advised utilizing Kadha (herbal tea/decoction) composing basil, cinnamon, black pepper, dry ginger, and raisin and golden milk to boost the immune system as a prophylactic measure against COVID-19. Due to the complex composition of multiple phytoconstituents from all these medicinal plants, the mixture of this combination could modulate multiple proteins and would help to boost the immune system which can be explained via network pharmacology and gene-set enrichment analysis. Network pharmacology and gene set enrichment analysis are well-accepted approaches to identify the disease target, lead hit molecules and modulated pathways via "multiple component-protein interactions" [9-11].

Boosting of the immune system involves the modulation of multiple proteins that are involved in the homeostatic regulation. In the present analysis, we identified the modulation of multiple pathways that are related to infectious/non-infectious diseases and the immune system. A subject suffering from 
infectious/non-infectious diseases possesses a lower immune system [12]; are at higher risk to be affected by COVID-19. Hence, the herbal tea which has been recommended by the AYUSH is not limited over the boosting of the immune system but also may modulate other pathways which are involved in the pathogenesis of multiple diseases provides beneficial effect to the patients with diabetes and hypertension who cannot undergo to the pharmacotherapy of 4-hydroxy quinoline.

Enrichment analysis of modulated proteins identified the regulation of HIF-1, p53, PI3K-Akt, MAPK, cAMP, Ras, Wnt, NF-kappa B, IL-17, TNF, and cGMP-PKG signaling pathway which are directly involved in boosting the immune system. The task of HIF-1a has been reported to be dysregulated in viral infection which is involved to boost the immune system by regulating the task of macrophages, neutrophils, dendritic cells, and lymphocytes during the hypoxic condition [13]; primarily occurs in COVID-19 infection due to improper exchange $\mathrm{O}_{2} / \mathrm{CO}_{2}$ in lungs [14]. In the present study, we identified five genes i.e. ALDOA, FLT1, HMOX1, NOS2, and TIMP1 to be modulated related to this pathway. Further, PI3K-Akt functions as a rheostat in orchestrating the differentiation of memory CD8 T cells [15] which further regulate the functioning of multiple chemokines and cytokines [16] from multiple pathways like NF-kappa B, IL-17, and TNF signaling pathway which were found to be modulated in the present study. Hence, the next approach to boost the immune system by suggested Kadha could occur via regulation of PI3K-Akt, NF-k $\beta$, interleukin, and TNF mediated cytokine regulation. Further in infectious diseases including viral infection MAPK pathway gets targeted by pathogens. Since this pathway is involved in the synthesis of immunomodulatory cytokines like interleukins and TNF-a via the activation of p38 MAPK pathways, modulation of this pathway could play important coordination with an immune response via the promotion of Th1 and Th2 against extracellular infectious agents [17]; has been regulated in the present study via the modulation of six proteins i.e. CD14, FLT1, HSPA6, RAC1, RAP1A, TNFRSF1A. Further, in COVID-19 there is an increase in cell apoptosis and necrosis in lung tissue. As the phytoconstituents were also predicted to modulate the Ras signaling pathway, the suggested herbal tea could also function in multiple cellular tasks including the regulation of cell survival and proliferation [18]. Additionally, we also identified the multiple pathways (Table S2) which get modulated in the pathogenesis of multiple infectious (bacterial/viral) and non-infectious diseases (diabetes, obesity, hypertension, etc) in which the immune system is compromised. Hence, the intake of this tea would also add a beneficial effect to maintain their daily lifestyle and also may improve the immunity system.

Since the AYUSH suggested the intake of the composition as an herbal tea and is to be taken orally, we attempted to identify the probable lead hits to get absorbed from the human intestinal tract in which the majority of the compounds were predicted to be absorbed from the gastrointestinal tract. Based on the Rule of Five, we identified camphoratin D to possess the highest drug-likeness score. Similarly, camphoratin B was predicted to have the highest human oral bioavailability. However, the single-molecule may not be as effective compared to the advised herbal tea as the amount required to boost the immune system may not sufficient enough. Hence, intake of the multiple compounds in the form of herbal tea as suggested by AYUSH could be more beneficial rather than a single molecule for boosting the immune 
system as a prophylactic against COVID-19 and could be helpful in subjects who are suffering diabetes and hypertension in which 4-hydroxychloroquine treatment cannot be proceed.

\section{Conclusion}

The present study utilized the system biology tools to assess the immunomodulatory effect of Kadha (herbal tea) suggested by AYUSH as a prophylactic approach against COVID-19. In this study, we identified the suggested herbal tea may not be limited to enhance the immune system but also may regulate multiple proteins/pathways involved in the infectious and non-infectious diseases which could be beneficial to those subjects in which 4-hydroxy quinoline cannot be administered.

\section{Declarations}

\section{Conflict of interest}

The authors declare that they have no conflict of interest.

\section{Foundation project}

The authors have no support or funding to report.

\section{Acknowledgment}

Authors are thankful to Principal KLE College of Pharmacy, Belagavi, KLE Academy of Higher Education and Research (KAHER) Belagavi for his support.

\section{Authors Contribution}

Yadu Nandan Dey made the concept and designed the study. Pukar Khanal reviewed literature, carried out the work and drafted the manuscript. Taaza Duyu assisted in the mining of data and drafting/reviewing the manuscript. BM Patil and Yadu Nandan Dey have contributed to suggesting refining the protocol and final draft of the manuscript. Ismail Pasha contributed to the final refining of the manuscript.

\section{References}

1. Opitz B, van Laak V, Eitel J, Suttorp N. Innate immune recognition in infectious and noninfectious diseases of the lung. Am J Respir Crit Care Med. 2010;181(12):1294-1309.

DOI:10.1164/rccm.200909-1427SO

2. Nicholson LB. The immune system. Essays Biochem. 2016;60(3):275-301. DOI:10.1042/EBC20160017

3. Ministry of AYUSH. Ayurveda's immunity boosting measures for self care during COVID 19 crisis. 2020. Available at: https://www.ayush.gov.in/docs/123.pdf. Accessed on: 12 April 2020 
4. Lagunin A, Ivanov S, Rudik A, Filimonov D, Poroikov V. DIGEP-Pred: web service for in silico prediction of drug-induced gene expression profiles based on structural formula. Bioinformatics. 2013;29(16):2062-2063. DOI:10.1093/bioinformatics/btt322

5. Szklarczyk D, Morris JH, Cook H, et al. The STRING database in 2017: quality-controlled proteinprotein association networks, made broadly accessible. Nucleic Acids Res. 2017;45(D1):D362-D368. DOI:10.1093/nar/gkw937

6. Shannon P, Markiel A, Ozier O, et al. Cytoscape: a software environment for integrated models of biomolecular interaction networks. Genome Res. 2003;13(11):2498-2504. DOl:10.1101/gr.1239303

7. Lipinski CA. Lead- and drug-like compounds: The rule-offive revolution. Drug Discov Today Technol 2004;1(4):337-41.

8. Yang H, Lou C, Sun L, et al. admetSAR 2.0: web-service for prediction and optimization of chemical ADMET properties. Bioinformatics. 2019;35(6):1067-1069. DOI:10.1093/bioinformatics/bty707

9. Khanal P, Patil BM, Mandar BK, Dey YN, Duyu T. Network pharmacology-based assessment to elucidate the molecular mechanism of anti-diabetic action of Tinospora cordifolia. Clin Phytosci 2019; 5:35. https://doi.org/10.1186/s40816-019-0131-1

10. Khanal P, Patil BM. Gene set enrichment analysis of alpha-glucosidase inhibitors from Ficus benghalensis. Asian Pac J Trop Biomed 2019;9(6):263-70.

11. Khanal P, Patil BM. a-Glucosidase inhibitors from Duranta repensmodulate p53 signaling pathway in diabetes mellitus. Adv Tradit Med (ADTM) https://doi.org/10.1007/s13596-020-00426-w

12. NCBI (US) 1998. Genes and Disease [Internet]. Bethesda (MD): National Center for Biotechnology Information (US); 1998-. Diseases of the Immune System. Available from:

https://www.ncbi.nlm.nih.gov/books/NBK22243/ Accessed on 17 April 2020

13. Palazon A, Goldrath AW, Nizet V, Johnson RS. HIF transcription factors, inflammation, and immunity. Immunity. 2014;41(4):518-528. DOI:10.1016/j.immuni.2014.09.008

14. Mason RJ. Pathogenesis of COVID-19 from a cell biology perspective. Eur Respir J. 2020;55(4):2000607. Published 2020 Apr 16. DOI:10.1183/13993003.00607-2020

15. Kim EH, Suresh M. Role of PI3K/Akt signaling in memory CD8 T cell differentiation. Front Immunol. 2013;4:20. Published 2013 Feb 1. DOI:10.3389/fimmu.2013.00020

16. Kenway-Lynch CS, Das A, Lackner AA, Pahar B. Cytokine/Chemokine responses in activated CD4+ and CD8+ T cells isolated from peripheral blood, bone marrow, and axillary lymph nodes during acute simian immunodeficiency virus infection. J Virol. 2014;88(16):9442-9457.

DOI:10.1128/JVI.00774-14

17. Soares-Silva M, Diniz FF, Gomes GN, Bahia D. The Mitogen-Activated Protein Kinase (MAPK) Pathway: Role in Immune Evasion by Trypanosomatids. Front Microbiol. 2016;7:183. Published 2016 Feb 24. DOI:10.3389/fmicb.2016.00183

18. Johnson DS, Chen YH. Ras family of small GTPases in immunity and inflammation. Curr Opin Pharmacol. 2012;12(4):458-463. DOI:10.1016/j.coph.2012.02.003 
Figures

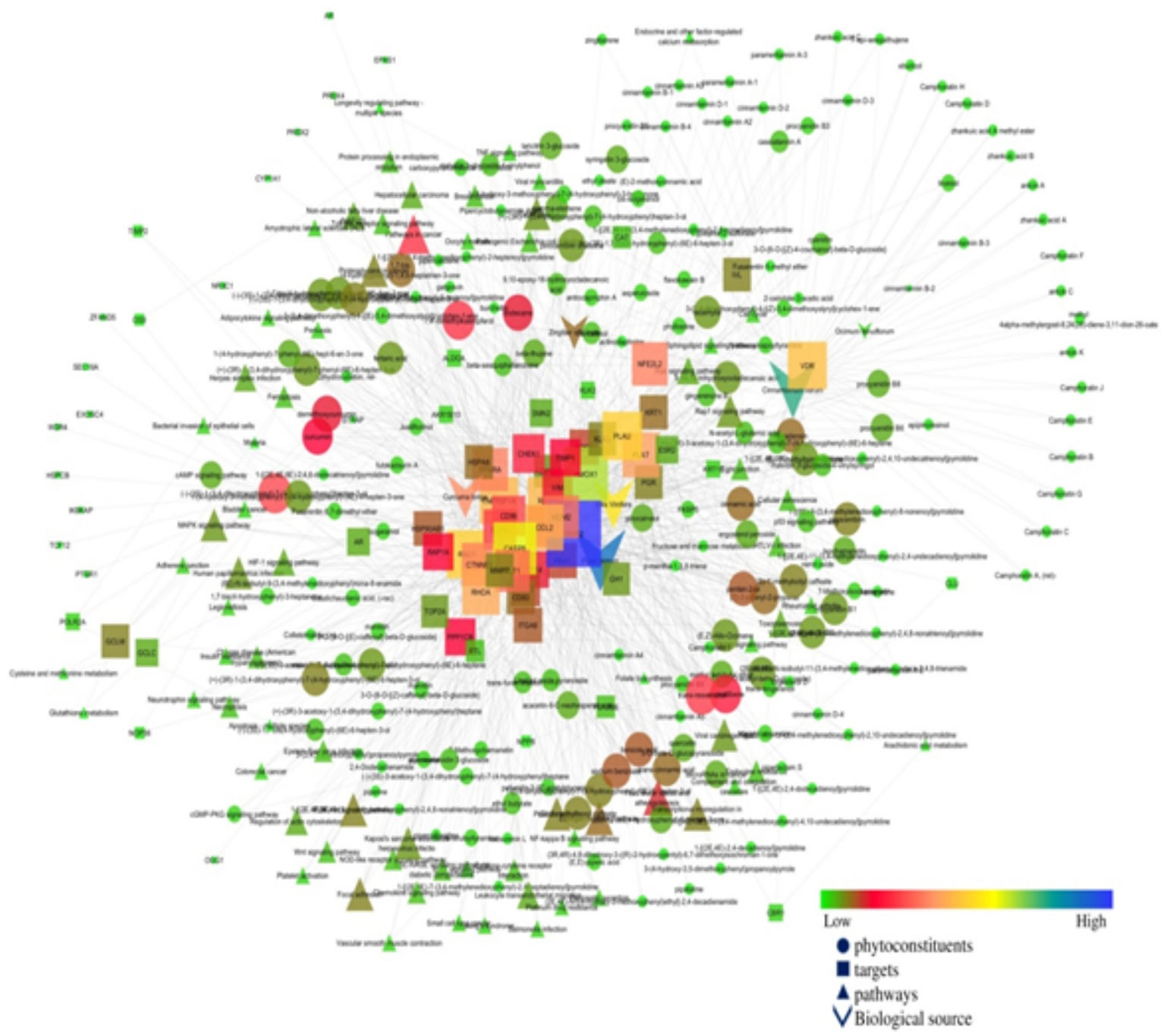

Figure 1

Interaction of phytoconstituents with their proteins and regulated pathways 


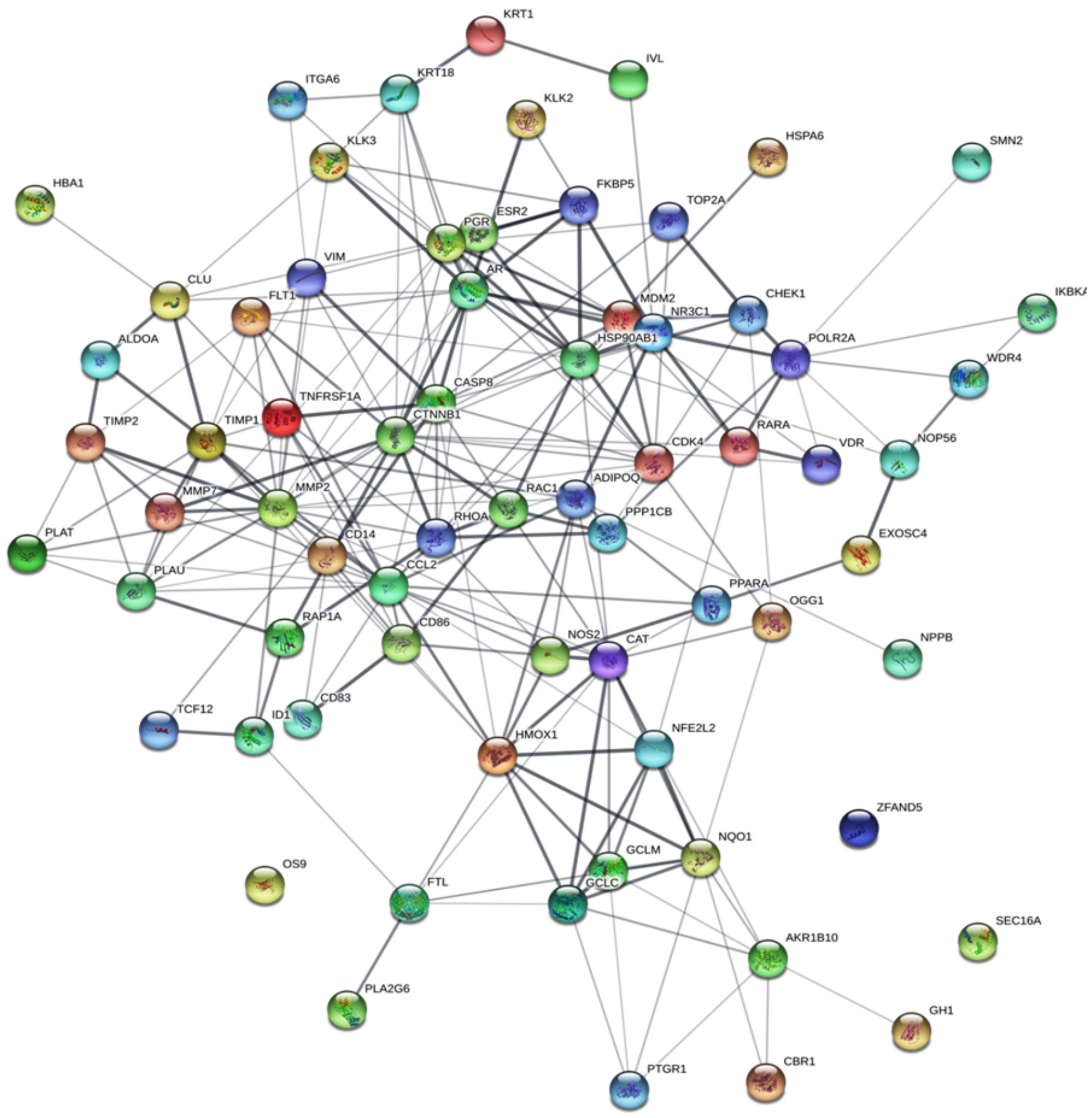

Figure 2

Protein-protein interaction of regulated proteins by the phytoconstituents from herbal tea 
a

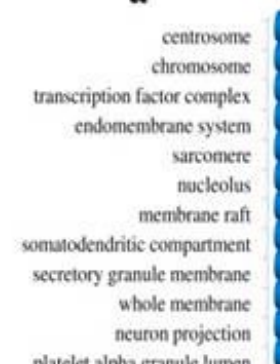

platelet alpha granule lumen

intracellular organelle

sperm head

intracellular part

microtubule organizing center

perinuclear region of cytoplasm

intracellular

chromatin

tertiary granule

cytoskeleton

receptor complex

glutamate-cysteine ligase complex

cytoplasmic vesicle

nucleoplasm

nuclear lumen

vesicle

membrane-bounded organelle

secretory granule lumen

intracellular organelle part organelle part

cytoplasmic vesicle part

ficolin-1-rich granule lumen cell surface

intracellular non-membrane-bounded organelle

eytoplasmic vesicle lumen
cytoplasmic part

ficolin-1-rich granule

protein-containing complex

secretory granule

cytoplasm

extracellular region part

cytosol

intracellular organelle lumen

extracellular space

extracellular region

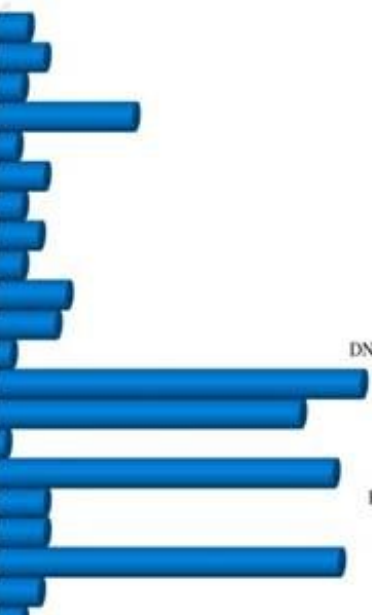

?

\section{b} catalybic activity, acting on a proscin
trumscription cofactor binding
receptor regulator astivity

oxidonductase activity, acting on NAD(P)H

DNA-thinding transcription factor tinding metal ion binding protein $\mathrm{C}$-teminus binding ubiçaitin protein ligase binding mall molecule binding hormone binding sigaling receptor astivity hermone receptor binding

A binding transcriptice activater activity, RNA ATPase binding ive bisding lipid binding tan protcia bisding

protein containing complex binding RNA polymerase If regulatory region sequence. molecular transdocer activity metalkendepeptidase inhibiaror activity transcription factor binding Beme binding
procecin kinase binding

RNA polymerase II proximal promader soquenecexidoreductase activity, acting on NADIPJH, hens:

RNA polymerase Il trancription factar hinding beat shock protein binding tistane deacety lase binding oreanic cyclic compound binding bydrolase activity

ATP-dependent protein binding carborylic acid binding endopeptidase astivity

heterocyclic compound binding

protein beterodimerization activity

histone methyltransferase bioding disordered domain specific binding Rho GDP-disweciatioe inhibitor binding catalytic activity

gluamate-cysteinc ligase astivity caffold protcia binding serine-type endopeptidase activity protein dimerization activity identical protein binding steroid binding senine hydrolase activity prokein domain specific binding binding rinc ion bisdin transition netal iee binding signaling receptor binding enzyme binding seroid bormone recepeor activity nuclear receptor activity protein binding
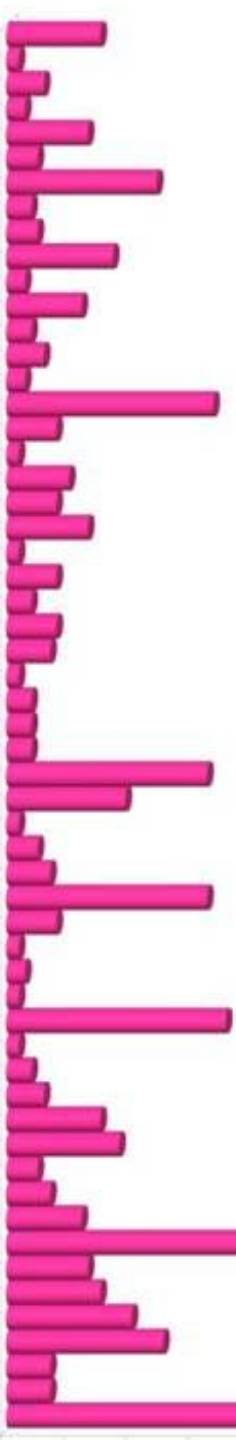

c

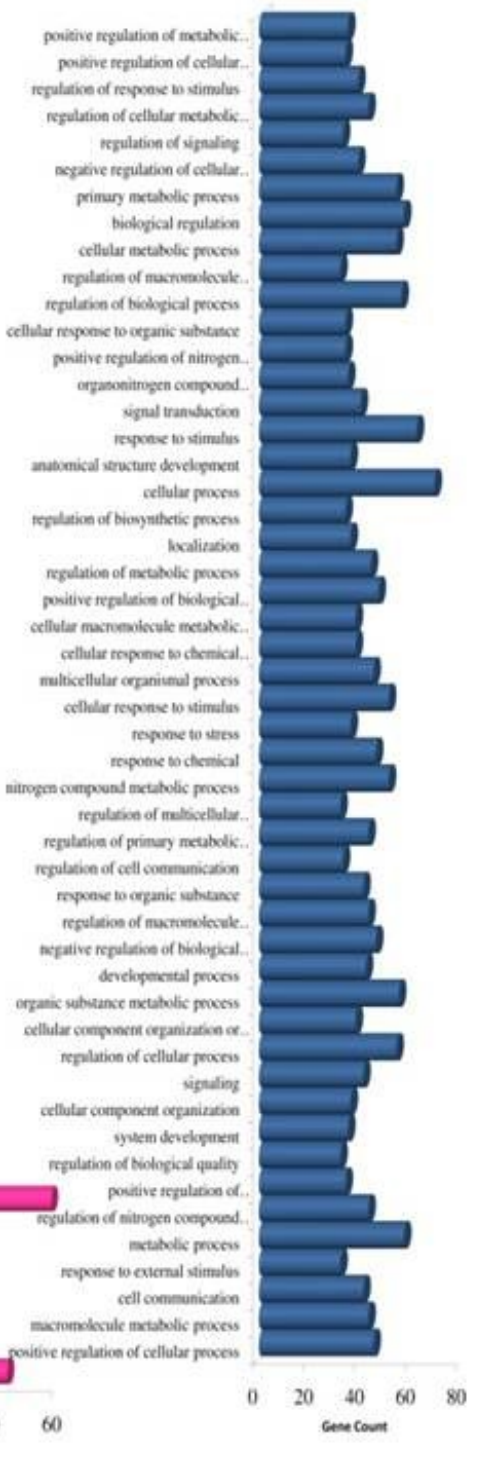

Figure 3

GO gene analysis of modulated proteins (a) cellular components (b) molecular function and (c) biological process 


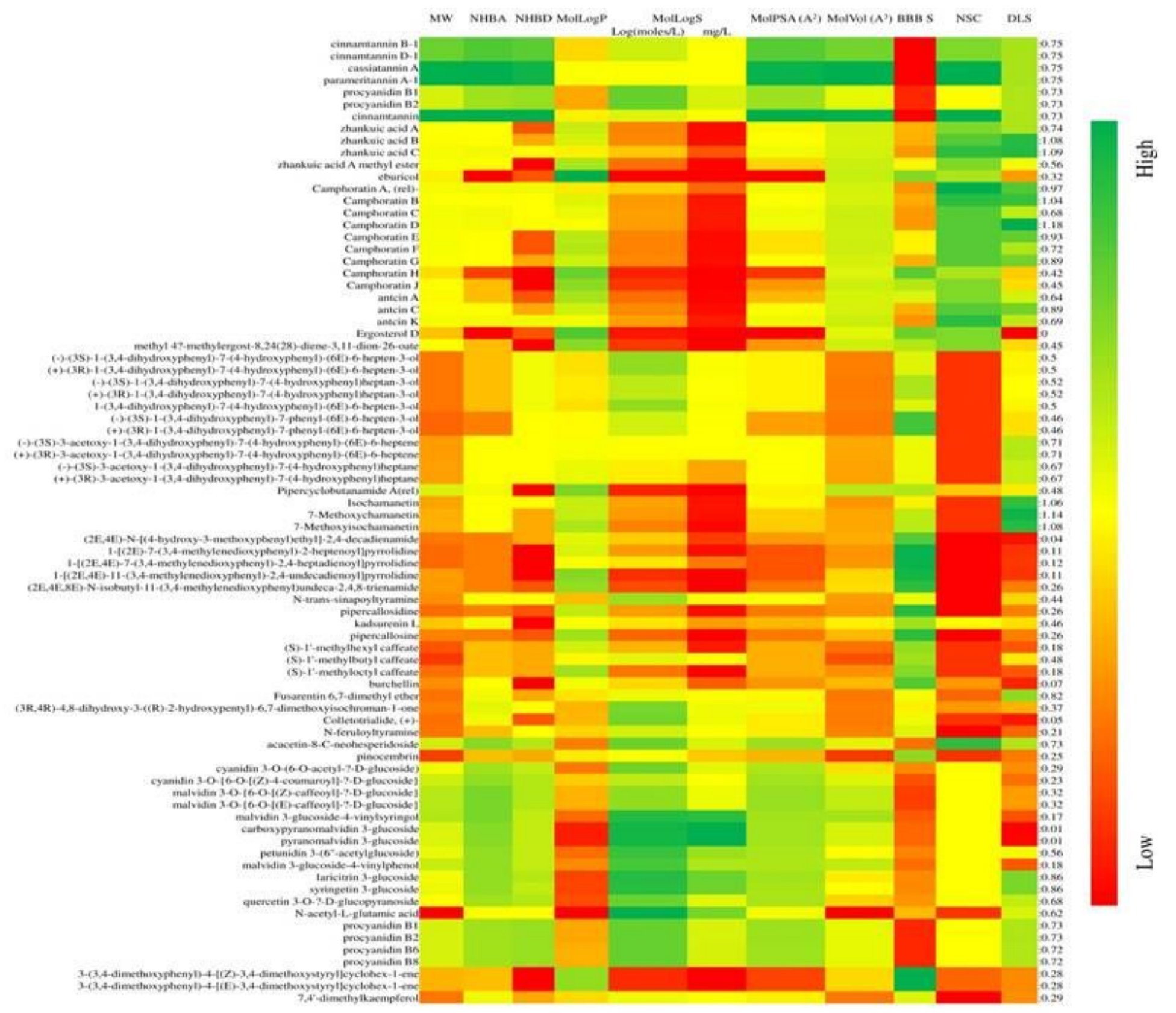

Figure 4

Druglikeness score of phytoconstituents. MW: Molecular weight, NHBA: Number of hydrogen bond acceptor, NHBD: Number of hydrogen bond donor, BBB S: Blood brain barrier Score, NSC: Number of stereo centres, DLS: Druglikeness score 


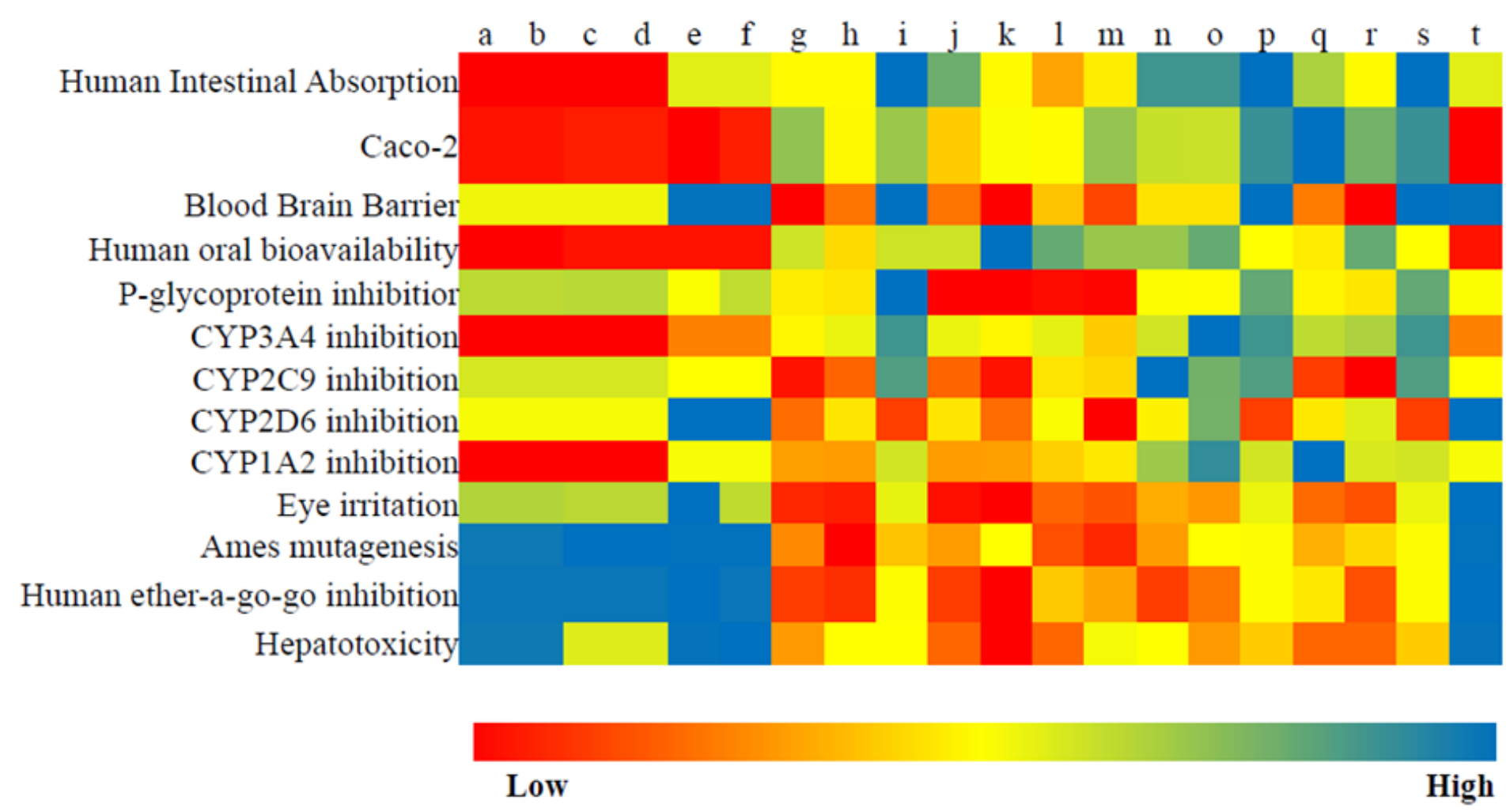

\section{Figure 5}

Fig. 5:cinnamtannin B-1, (b) cinnamtannin D-1, (c) cassiatannin A, (d) parameritannin A-1, (e) procyanidin B2, (f) cinnamtannin A2, (g) zhankuic acid B, (h) zhankuic acid C, (i) zhankuic acid A methyl ester, (j) Camphoratin A, (rel)-, (k) Camphoratin B, (I) Camphoratin C, (m) Camphoratin D, (n) Camphoratin E, (o) Camphoratin F, (p) Camphoratin J, (q) antcin A, (r) antcin C, (s) methyl 4-a-methylergost-8,24(28)-diene3,11-dion-26-oate and ( $\mathrm{t}$ ) procyanidin $\mathrm{B} 1$

\section{Supplementary Files}

This is a list of supplementary files associated with this preprint. Click to download.

- Supplementaryfile.docx 